EPiC Series in Engineering
Volume 3, 2018, Pages 917-925
HIC 2018. 13th International
Conference on Hydroinformatics

\title{
Simulation of extreme hydrometeorological events under tropical conditions using a distributed hydrological model
}

\author{
Sara Patricia Ibarra-Zavaleta ${ }^{1,2}$, Annie Poulin $^{3}$, Mariana Castañeda- \\ González ${ }^{3}$, Rabindranarth Romero-López ${ }^{2}$, Rosario Landgrave ${ }^{4}$ and Ernesto \\ Ruelas Inzunza ${ }^{1}$ \\ ${ }^{1}$ Instituto de Biotecnología y Ecología Aplicada, Universidad Veracruzana, Mexico \\ 2 Facultad de Ingenieria Civil, Universidad Veracruzana, Mexico \\ ${ }^{3}$ Département de génie de la Construction; École de Technologie Supérieure, Québec, Canada \\ ${ }^{4}$ Departamento de Ecologia Funcional, Instituto de Ecología, A.C., Mexico \\ saibarra@uv.mx, Annie.Poulin@etsmtl.ca, \\ castanedagonzalezmariana@gmail.com, rabromero@uv.mx, \\ rosario.landgrave@inecol.mx and eruelas@uv.mx
}

\begin{abstract}
Change in climatic conditions worldwide has increased the frequency and severity of extreme hydrometeorological events (EHEs). Mexico is an example of this: the country has been affected by the occurrence of EHEs leading to important economic, social, and environmental losses. The objective of this investigation was to apply a Canadian Distributed Hydrological Model (DHM) to tropical conditions, and to evaluate its capacity to simulate flows in a basin in the central Gulf of Mexico. Additionally, we used this calibrated and validated DHM to predict streamflow before the occurence of an EHEs. The results of the DHM show satisfactory goodness-of-fit indicators between the observed and simulated flows in the calibration process $(\mathrm{NSE}=0.83, \mathrm{RSR}=0.41$ and BIAS $=-4.3$ ), as well as its validation $(\mathrm{NSE}=0.775$, $\mathrm{RSR}=0.4735$ and $\mathrm{BIAS}=2.45)$. The DHM showed its applicability to streamflow simulation and confirmed a reliable efficiency in the modeling of thirteen EHEs (NSE $=0.78 \pm 0.13$, RSR $=0.46 \pm 0.14$, and PBIAS $=-0.48 \pm 7.5$ ). DHM can serve as a tool to identify vulnerabilities before floods and assist in devising more rational and sustainable management of water resources.
\end{abstract}

\section{Introduction}

The observed change in climatic conditions worldwide has caused an increase in the frequency and severity of extreme hydrometeorological events (EHEs) (IPCC, 2007). Because of its geographic 
location and physical characteristics, Mexico is a vulnerable country due to the occurrence of EHEs, primarily the formation and development of tropical cyclones on the Pacific coast and the Gulf of Mexico that affect $60 \%$ of the national territory. Due to its geographical location, orography, climate, and human settlements in high-risk areas, the state of Veracruz, located in the east coast of the country, is a highly vulnerable area exposed to these phenomena (Guzmán et al., 2011). The state was affected by three very large EHEs: tropical storms (in 2000) and hurricanes (Stan in 2005 and Karl in 2010) causing substantial economic, social, and environmental losses. Despite the impact of EHEs in recent decades, scientists still face many limitations regarding the availability and quality of hydrometeorological data (GEV, 2016). Considering the deficiencies in the data, and the urgency to prevent further socio-economic losses due to floods, it is necessary to develop science-based tools for an accurate prediction of their consequences (CENAPRE, n.d.). One solution is the use of hydrological simulation models, because their low operating cost (Francés \& Benito, 1995). The aim of this research was to evaluate the response of the Distributed Hydrological Model HYDROTEL to one of its applications: the forecast of runoff from EHEs.

Case study: La Antigua River Basin in Veracruz, Mexico. This watershed is located in the central part of the Gulf of Mexico, between 19 $12^{\prime \prime}-19^{\circ} 35^{\prime \prime} \mathrm{N}$, and between $96^{\circ} 30^{\prime \prime}-97^{\circ} 13^{\prime \prime} \mathrm{W}$. The watershed, is exposed to a great variety of EHEs, such as hurricanes, tropical storms, and floods. (INEGI, 2012). Our study site has an approximate area of $1,620.6 \mathrm{~km}^{2}$ with elevations ranging from $82-4,204 \mathrm{~m}$ a.s.1. Due to its large altitudinal variation, there are great climatic variations and different vegetation covers throughout the basin. The precipitation in the watershed varies between $1,500-2,500 \mathrm{~mm}$, whilst the average annual temperature is between $18-26^{\circ} \mathrm{C}$ (CONAGUA, 2014b). The main soil types present in the study area are acrisols $(68.6 \%)$ located in the north rim of the basin, luvisols $(23.8 \%)$ at the basin's center, podzol (3.6\%), and vertisols (4\%) in its southern portion (INEGI, 2013a). The types of land use include agriculture (57.3), urban (2.1\%), forest (17.8\%), and pastureland (22.8\%) (INEGI, 2013b).

\section{Materials and Method}

We divided this research in five stages: 1) Data collection and analysis; 2) Application of the HYDROTEL model to the basin under study; 3) Calibration of the hydrological model; 4) Spatial and temporal validation of the hydrological model, and 5) Applications of distributed hydrological model to simulate the streamflow of extreme hydrometeorological events.

\subsection{Data collection and analysis}

The essential data for distributed hydrological modeling requires two types of information: hydrometeorological and physiographic datasets. The first class of data is required on a daily basis for the following variables: minimum temperature, maximum temperature, total precipitation, and streamflow at the outlet of the basin. The second class of data includes the digital elevation model, land uses, and soil types. Subsequently, the data was subjected to a quality control, with the objective of detecting errors in the observation data that could be caused mainly by difficulties in the measurement plus errors due to manipulation and data capture and storage processes. These processes apply to the identification of errors, such as the maximum temperature being greater than the minimum or the precipitation being negative. Other errors have been filtered because they are outside the range of values of the region, such as temperatures below $-25^{\circ} \mathrm{C}$ and above $50^{\circ} \mathrm{C}$ (Aguilar, 2013).

Description of the geographic information system PHYSITEL PHYSITEL was developed at the INRS-ETE (Institut national de la recherche scientifique centre Eau, Terre et Environnement) in Québec, Canada, in 1985 (Fortin, Moussa, Bocquillon, \& Villeneuve, 1995). It was designed to generate the physiographic database of the HYDROTEL hydrological model. PHYSITEL allows the integration of various types of data from remote sensing and geographical information systems (GIS). The data 
used by this system are both raster (DEM, soil types, and land use) and vector (hydrographic network, limit of the watershed). PHYSITEL allows characterizing the internal flow structure of a watershed from a numerical elevation model. The determination of the internal flow structure serves as a basis for the characterization of the hydrological units (or sub-basins) that represent the spatial simulation units (Fortin, 2000b). The information on the surface conditions that affects the "evaporation-flowinfiltration" can be integrated to determine the hydrological parameters of the calculation units. PHYSITEL defines the watershed into relatively homogeneous hydrological units (RHHUs) (Rousseau et al., 2011). These hydrological units are established to contain only one section of the hydrological network. Each of these units is assigned a single value for soil type, which corresponds to the dominant formation for the entire unit. Likewise, each one of these units is assigned the percentages represented by each land-use class. At the end, PHYSITEL allows us to export to HYDROTEL the following data: altitude, slope, flow orientation, hydrographic network, and delineation of each RHHU, based on a user defined threshold that is set according to the desired level of detail (Fortin, 2000b; Rousseau et al., 2011).

\subsection{Application of the Distributed Hydrological Model HYDROTEL}

HYDROTEL was also developed by the INRS-ETE. It is a spatially distributed hydrological model with physical bases specifically developed to facilitate the use of remote sensing and GIS data. This approach brings a better representation of the spatial variability of the physiographic characteristics of river basins (topography, land use, soil types, etc.) and of the meteorological systems that affect the basins (Fortin, 2000a). HYDROTEL comprises six submodules, which run in successive steps. Each submodule simulates a specific hydrological process. The first submodule is the Interpolation of Meteorological Data, the second submodule is the Snow Cover Estimation, the third submodule is the Potential Evapotranspiration Estimation (PET), the fourth submodule is the Vertical Water Balance, the fifth submodule is the Overland Routing, and the sixth and last submodule is the Channel Routing (Fortin J-P et al., 2001).

\subsection{Calibration of the Distributed Hydrological Model}

In this study, the Dynamically Dimensioned Search (DDS) algorithm was used. It is designed to be an efficient tool for calibration of complex and large-parameter-space hydrological models. The DDS algorithm automatically scales the search space to decrease the number of model evaluations required to reach the optimal region of best-quality fitness function (for more details about the DDS algorithm, the reader is referred to Tolson and Shoemaker (Tolson \& Shoemaker, 2007). The calibration was evaluated by the statistical indicators. The indicators used in this study are the ones recommended by Moriasi et al. (2007) (Moriasi et al., 2007), namely, the Nash-Sutcliffe efficiency (NSE) index, which is equal to one minus the ratio of the Mean Square Error (MSE) and standard deviation of measured data time series (H. V Gupta, Kling, Yilmaz, \& Martinez, 2009). The NSE (Nash \& Sutcliffe, 1970) is computed as the relative magnitude of the residual variance compared to the variance of the observed data "information". The NSE is shown in equation 1 (see also Table 1 for the meaning of NSE values).

$$
N S E=1-\left[\frac{\sum_{i=1}^{n}(q(i)-q(i))^{2}}{\sum_{i=1}^{n}(q(i)-\bar{q})^{2}}\right]
$$

Where $\widehat{\boldsymbol{q}}(\boldsymbol{i})$ is the ith observation for the constituent being evaluated, $\boldsymbol{q}(\boldsymbol{i})$ is the ith simulated value for the constituent being evaluated, $\overline{\boldsymbol{q}}$ is the mean of observed data for the constituent being evaluated, and $\mathrm{n}$ is the total number of observations. NSE ranges between $-\infty$ and 1.0 ( 1 inclusive), with NSE $=1$ meaning a perfect match between simulated and observed values. Values between 0.0 and 1.0 are 
generally viewed as acceptable levels of performance (Table 1), whereas negative values mean that the mean of observed data is a better predictor than the simulated data (Nash \& Sutcliffe, 1970). The RMSE-observations standard deviation ratio (RSR): is calculated as the ratio of the Root Mean Square Error (RMSE) and standard deviation of measured data (equation 2) and was developed based on the recommendation by Singh et al. (Singh, Knapp, Arnold, \& Demissie, 2005) RSR -combines both an error index and the additional information recommended by Legates and McCabe (Legates \& McCabe, 1999). RSR of zero indicates the optimal value, while RSR $>0.7$,represents unsatisfactory model performance (Hamaamin, Nejadhashemi, Zhang, \& Giri, 2016) as shown in Table 1.

$$
R S R=\frac{R M S E}{S T D E V_{O B S}}=\frac{\left[\sqrt{\sum_{i=1}^{n}(q(i)-q(i))^{2}}\right]}{\left[\sqrt{\sum_{i=1}^{n}(q(i)-\bar{q})^{2}}\right]}
$$

Percent bias (PBIAS) is the relative bias of data being evaluated, expressed as a percentage. PBIAS measures the average tendency of the simulated data to be larger or smaller than their observed counterparts (H. V. Gupta, Sorooshian, \& Yapo, 1999). The optimal value of PBIAS is 0.0, with lowmagnitude values indicating accurate model simulation. Positive values indicate model underestimation PBIAS and negative values indicate model overestimation PBIAS (Legates \& McCabe, 1999; Singh et al., 2005) (see Table 1). PBIAS is calculated with equation 3:

\begin{tabular}{cccc} 
PBIAS $=\left[\frac{\sum_{i=1}^{n}(q(i)-q(i)) \times 100}{\sum_{i=1}^{n} q(i)}\right]$ & & \\
\hline PBIAS & NSE & RSR & Internretation of the Model \\
\hline PBIAS $< \pm 10$ & $0.75<\mathrm{NSE}<1.0$ & $0.00<\mathrm{RSR}<0.50$ & Very good \\
$\pm 10<$ PBIAS $< \pm 15$ & $0.65<\mathrm{NSE}<0.75$ & $0.50<\mathrm{RSR}<0.60$ & Good \\
$\pm 15<$ PBIAS $< \pm 25$ & $0.50<\mathrm{NSE}<0.65$ & $0.60<\mathrm{RSR}<0.70$ & Satisfactory \\
PBIAS $> \pm 25$ & $\mathrm{NSE}<0.50$ & $\mathrm{RSR}>0.70$ & Unsatisfactory \\
\hline
\end{tabular}

Table 1: Interpretation of statistical parameters for calibration and validation (Moriasi et al., 2007).

\subsection{Spatial and temporal validation of the DHM}

The process of temporal validation of a model consists in demonstrating that the model is able to make predictions at a specific site for periods outside the calibration period. Hence, it can be said that a model has been validated if its accuracy and predictive ability falls within acceptable errors or limits (Refsgaard \& Knudsen, 1996). The calibration and validation was based on the hydrometric data of a control station located at the outlet of the studied river basin. The spatial validation process was carried out by applying the model to predict streamflow at other points within the basin. The validation was done with the same parameters obtained from calibration based on the hydrometric output station.

\subsection{Simulation of extreme hydrometeorological events}

Once the distributed hydrological model (HYDROTEL) was calibrated and validated, we simulated the EHEs that affected the study area from 1990-2009 in the study area (compiled from the SMN and underground weather reports), and subsequently evaluated its performance indicators (NSE, RSR and PBIAS). 


\section{Results}

\subsection{Review and analysis of the available hydrometeorological data}

We first selected 22 meteorological stations based on two conditions. The first selection criterion was temporality, ensuring that the selected stations have information over the time period, for which streamflows are available i.e. from 1 Jan. 1990-31 Dec. 2009. The second criterion ensured that selected stations were located within the buffer of $5 \mathrm{~km}$ from the study watershed. Meteorological data were obtained from the National Weather Service (Servicio Meteorológico Nacional—SMN) (SMN, 2013) and hydrometric data (stations H28125-outlet, H28133, and H28134, all within the river basin) were obtained from the National Data Bank on Surface Water (Banco Nacional de Aguas SuperficialesBANDAS) (CONAGUA, 2014a) for the same period.

\subsection{Selecting algorithms for the simulation of hydrological processes}

The study area covers $1,621 \mathrm{~km}^{2}$, it was discretized in 33 hydrological units or RHHUs with an average area of $50 \mathrm{~m}^{2}$. Then percentages of each soil type and predominant soil texture were added to each RHHU. The following simulation options were selected for each one of the HYDROTEL submodules (see section 2.2): (i) Interpolation of meteorological data: weighted mean of nearest three stations; (ii) Snow cover estimation: mixed approach (deg. day-energy balance, which is the only available option); (iii) Potential evapotranspiration: Hydro-Québec; (iv) Vertical water balance: three layer vertical water balance (BV3C); (v) Overland routing: kinematic wave (which is the only available option) and last, (vi) Channel routing: kinematic wave (Fortin et al., 1995).

\subsection{Calibration and validation of the DHM (HYDROTEL)}

The parameters of hydrological model were automatically calibrated using the Dynamically Dimensioned Search (DDS) algorithm in order to achieve an acceptable level of statistical performance according to Moriasi et al. (2007). The three statistical indicators introduced in section 2.3 were used: NSE, RSR and PBIAS. Split Sample, was used for calibration and validation process. The data time series that was used for calibration spans from 1 Jan. 1990-31 Dec. 1999 (10 years). The following criteria lead to the choice of this 10-year period: (1) The length remained reasonable due to computational time considerations with HYDROTEL; (2) The years had to be consecutive to facilitate the execution of the simulation with HYDROTEL, both for the calibration and validation periods and (3) The availability of hydrometeorological information.

Spatial and Temporal validation of Hydrologic modeling. Temporal validation of the model was performed over a 10-year period that spans from 1 Jan. 1990-31 Dec. 1999. Statistical indicators (NSE, PBIAS and RSR) that were calculated using the daily and monthly observed and simulated streamflows for the calibration (1990-1999) and validation (2000-2009) periods in the La Antigua Basin are summarized below (Table 2). The main outcome is that the statistical indicators are systematically higher in the monthly scale. It is probably explained by the fact that monthly values are averages of already very good daily simulated values. In the monthly averages, the variations that affect the indicators on a smaller temporal time step are smoothed. It was also detected that PBIAS values showed that the model underestimated the values during the calibration and validation periods. In conclusion, the results are satisfactory according to Moriasi et al. (2007). 


\begin{tabular}{cccccc}
\hline Process & Statistic & Daily & Description & Monthly & Description \\
\hline \multirow{3}{*}{ Calibration } & NSE & 0.8321 & Very Good & 0.929 & Very Good \\
& RSR & 0.41 & Very Good & 0.2685 & Very Good \\
& PBIAS & -4.3 & Very Good & -4.2834 & Very Good \\
\hline \multirow{3}{*}{ Validation } & NSE & 0.775 & Very Good & 0.909 & Very Good \\
& RSR & 0.4735 & Very Good & 0.3014 & Very Good \\
& PBIAS & 2.45 & Very Good & 2.188 & Very Good \\
\hline
\end{tabular}

Table 2: Statistical indicators that evaluate the performance of the calibration and validation of the DHM, calculated from daily and mean monthly time series, in La Antigua River basin.

The spatial validation was performed for two additional hydrometric stations (H28133 and H28134) located within the study area, for the same time (Table 3). It is worth noticing that these hydrometric stations were not considered for the calibration process. In general, the model performs well or very well with NSE values of 0.62 and 0.70 for daily streamflows, and NSE of 0.78 and 0.82 for monthly streamflows (Table 3).

\begin{tabular}{cccccc}
\hline Test points & Statistic & Daily & Description & Monthly & Description \\
\hline \multirow{3}{*}{ H28133 } & NSE & 0.62 & Good & 0.78 & Very Good \\
& RSR & 0.59 & Good & 0.39 & Very Good \\
& PBIAS & -5.83 & Very Good & -5.40 & Very Good \\
\hline \multirow{3}{*}{ H28134 } & NSE & 0.70 & Good & 0.82499 & Very Good \\
& RSR & 0.54 & Good & 0.45 & Very Good \\
& PBIAS & -6.86 & Very Good & -6.27 & Very Good \\
\hline
\end{tabular}

Table 3: Statistical parameters of performance in series from daily and monthly data for the two test points (H28133 and H28134) the evaluation period from 01/01/1990 to 31/12/1999.

\subsection{Streamflow simulation of hydrometeorological extreme events}

We selected thirteen EHEs to evaluate the performance of the DHM in simulating such events. The EHEs under study were chosen from the period 1990-2009. The performance of the rainfall-runoff model for seven hurricanes and six tropical storms (Table 4). Each EHE confirmed a reliable efficiency (NSE $0.78 \pm 0.13$, RSR $0.46 \pm 0.14$ and PBIAS $-0.48 \pm 7.5$ ).

\begin{tabular}{llllc}
\hline EHE & Year & NSE & RSR & PBIAS \\
\hline Hurricane Gert & 1993 & $0.87^{1}$ & $0.36^{1}$ & $3.69^{1}$ \\
Tropical Depression 5 & 1994 & $0.61^{2}$ & 0.62 & $-0.41^{1}$ \\
Major Hurricane Roxanne & 1995 & $0.70^{2}$ & $0.55^{2}$ & $6.50^{1}$ \\
Tropical Depression 6 & 1995 & $0.94^{1}$ & $0.25^{1}$ & $-1.82^{1}$ \\
Hurricane Dolly & 1996 & $0.54^{3}$ & $0.68^{3}$ & $10.67^{2}$ \\
Major Hurricane Mitch & 1998 & $0.68^{2}$ & $0.57^{2}$ & $-9.36^{1}$ \\
Tropical Depression 2 & 1999 & $0.79^{1}$ & $0.46^{1}$ & $-13.19^{2}$ \\
Major Hurricane Keith & 2000 & $0.64^{2}$ & $0.60^{3}$ & $0.86^{1}$ \\
Tropical Storm Matthew & 2004 & $0.93^{1}$ & $0.27^{1}$ & $4.58^{1}$ \\
Tropical Storm Jose & 2005 & $0.80^{1}$ & $0.45^{1}$ & $-8.92^{1}$ \\
Hurricane Stan & 2005 & $0.85^{1}$ & $0.38^{1}$ & $7.07^{1}$ \\
Tropical Storm Marco & 2008 & $0.87^{1}$ & $0.36^{1}$ & $-11.06^{2}$ \\
Hurricane Fred & 2009 & $0.86^{1}$ & $0.38^{1}$ & $5.10^{1}$ \\
\hline
\end{tabular}

Table 4: Results of the statistical indicators that evaluate the performance of HDM for the simulation of selected EHEs, in La Antigua River Basin. $\left({ }^{1}\right)$ Very-good, $\left({ }^{2}\right)$ Good, $\left({ }^{3}\right)$ Satisfactory and $\left({ }^{4}\right)$ Unsatisfactory 


\section{Discussion}

This research discusses the usefulness of the Distributed Hydrological Model HYDROTEL for operational hydrology applied to watersheds under tropical conditions. Our approach supports the application of the hydrological distributed model via a GIS (PHYSITEL), and allows a more precise characterization and with low-resource requirements of the watershed behavior, as described by Velásquez et al. (2007) (SMN, 2013). In our case study, the DHM (HYDROTEL) generated an adequate characterization of the flow processes and the hydrological conditions involved. The results of temporal and spatial calibration and validation of the La Antigua River Basin, shows satisfactory performance indicators (Table 2) at the outlet of the basin, as well as at two other test points (Table 3). In accordance with the Moriasi et al. (2007) scale, our results showed a reliable performance (Moriasi et al., 2007). The advantages of distributed modeling consisted mainly of: i) a better representation of the spatial variability hydrological cycle phenomena and ii) the possibility to obtain results at any point inside the basin, without the need to prefix them (a priori) and for interpolation methodologies. Conversely, its disadvantages were the great amount of high resolution data, and the high computational times for its processing. The application presented here shows that the DHM (HYDROTEL) can serve as a tool for decision-makers and help in the mitigation of the negative effects of EHEs. Our model performance indicators show the hurricane and tropical storm data, and its simulated flow with HYDROTEL, reproduces well the observed rainfall flow (see a Table 4). This projection can be used to forecast runoff of each affluent of the modeled basin prior to EHEs using meteorological forecasts and identify sites with potential flood or drought affections. Our research generates knowledge to improve hydrological modeling and streamflow forecasting. These elements could ease accurate and timely warnings that allow increasing the period to implement the emergency plans with the goal to reduce the number of victims, harms or injuries. There are other benefits that despite being secondary have a relevant importance. These include the reduction of economic losses in family economies offering time to safeguard some tangible and intangible assets.

\section{Conclusions}

This study demonstrates that the distributed hydrological model HYDROTEL is adaptable to tropical conditions according to our study basin in a watershed located in the Gulf of Mexico. The methodologies developed in this research can also be applied in other regions with similar characteristics. We suggest generating more detailed information for modeling work in future studies, such as a review of the efficiency of meteorological and hydrometric measurements in order to establish the optimal number of stations and their adequate distribution within a basin.

\section{References}

Aguilar, E. (2013). Aproximación a la homogeneización de una red regional de series climáticas a resolución diaria. Reporte Técnico CRC-SAS-2013-003. España.

CENAPRE. (n.d.). Atlas Nacional de Riesgos, Declaratorias de desastre y emergencia. Retrieved December 21, 2015, fromhttp://www.atlasnacionalderiesgos.gob.mx/index.php?option=com_content $\&$ view $=$ article \&id $=117 \&$ Itemid $=225$

CONAGUA. (2014a). Banco Nacional de Datos de Agua Superficiales (BANDAS). Retrieved January 1, 2014, from ftp://ftp.conagua.gob.mx/Bandas/Bases_Datos_Bandas

CONAGUA. (2014b). Estadísticas del agua en México 2014 (Comisión Nacional del Agua). (Consejo Veracruzano de Investigación Científica y Desarrollo Tecnológico, Ed.) (Edition 20). 
Comisión Nacional del Agua, Cd. de México, México. Retrieved from www.conagua.gob.mx

Fortin J-P, Turcotte, R., Massicotte, S., Moussa, R., Fitzback, J., \& Villeneuve, J.-P. (2001). Distributed watershed model compatible with remote sensing and GIS data. II: application to Chaudière Watershed. Journal of Hydrological Engineering, 6(2), 100-108.

Fortin, J.-P. (2000a). HYDROTEL. Retrieved December 12, 2016, from http://www1.ete.inrs.ca/activites/modeles/hydrotel/fr/accueil.htm

Fortin, J.-P. (2000b). PHYSITEL (Determination of the drainage structure ).

Fortin, J.-P., Moussa, R., Bocquillon, C., \& Villeneuve, J.-P. (1995). Hydrotel, un modèle hydrologique distribué pouvant bénéficier des données fournies par la télédétection et les systèmes d'information géographique. Revue Des Sciences de l'eau/Journal of Water Science,8(1),97-124.

Francés, F., \& Benito, J. (1995). La modelación distribuida con pocos parámetros de las crecidas. Ingeniería Del Agua, 2(diciembre), 7-24.

GEV. (2016). Plan Veracruzano de Desarrollo 2016-2018 (No. 476). Mexico.

Gupta, H. V., Sorooshian, S., \& Yapo, P. O. (1999). Status of automatic calibration for hydrologic models: Comparison with multilevel expert calibration. Journal of Hydrologic Engineering, 4(2), 135143.

Gupta, H. V, Kling, H., Yilmaz, K. K., \& Martinez, G. F. (2009). Decomposition of the mean squared error and NSE performance criteria: Implications for improving hydrological modelling. Journal of Hydrology, 377(1), 80-91.

Guzmán, N. Z., Bonilla, J., Maza, R., Cerán, V., Delgadillo, C., Ferrer, J., ... Orozco, I. (2011). Protección Civil. Programa Veracruzano de Educación 2011 - 2016. Xalapa, Veracruz. México.

Hamaamin, Y. A., Nejadhashemi, A. P., Zhang, Z., \& Giri, S. (2016). Bayesian Regression and Neuro-Fuzzy Methods Reliability Assessment for Estimating Streamflow.

INEGI. (2012). SIATL (Simulador de Flujos de Agua de Cuencas Hidrográficas). Retrieved January 1, 2013, from http://antares.inegi.org.mx/analisis/red_hidro/SIATL/

INEGI. (2013a). (Instituto Nacional de Estadistica Geografía e Informática) Cartas de uso del suelo y vegetación, Datos vectoriales escala 1:250 000 serie V. Retrieved August 8, 2013, from http://www.inegi.org.mx/geo/contenidos/recnat/usosuelo/Default.aspx

INEGI. (2013b). Conjunto de datos vectoriales de uso de suelo y vegetación escala 1:250 000, serie $V$ (capa unión) (2a ed.). México. Aguascalientes, Aguascalientes: Instituto Nacional de Estadística y Geografía.

IPCC. (2007). Resumen para Responsables de Políticas. En Cambio Climático 2007: Impactos y vulnerabilidad. Contribución del Grupo de Trabajo II al cuarto Informe de Evaluación del IPCC , Parry Martin, Canziani Osvaldo, Palutikof Jean, Van der Linden Pascala y Hanson Cl. Cambridge, Reino Unido.

Legates, D. R., \& McCabe, G. J. (1999). Evaluating the use of "goodness-of-fit" measures in hydrologic and hydroclimatic model validation. Water Resources Research, 35.1, 233-241.

Moriasi, D. N., Arnold, J. G., Van Liew, M. W., Binger, R. L., Harmel, R. D., \& Veith, T. L. (2007). Model evaluation guidelines for systematic quantification of accuracy in watershed simulations. Transactions of the ASABE, 50(3), 885-900. https://doi.org/10.13031/2013.23153

Nash, J. E., \& Sutcliffe, J. V. (1970). River flow forecasting through conceptual models. J. Hydrol., $10,282-290$.

Refsgaard, J. C., \& Knudsen, J. (1996). Operational validation and intercomparison of different types of hydrological models. Water Resources Research, 32(7), 2189-2202. https://doi.org/10.1029/96WR00896

Rousseau, A. N., Fortin, J. P., Turcotte, R., Royer, A., Savary, S., Quévy, F., ... Paniconi, C. (2011). PHYSITEL, a specialized GIS for supporting the implementation of distributed hydrological models. Water News-Official Magazine of the Canadian Water Resources Association, 31(1),18-20.

Singh, J., Knapp, H. V., Arnold, J. G., \& Demissie, M. (2005). Hydrological modeling of the iroquois river watershed using HSPF and SWAT1. Wiley Online Library:Hoboken, NJ, USA.

SMN. (2013). Información Climatológica. Retrieved January 17, 2014, from 
http://smn.cna.gob.mx/index.php?option $=$ com content\&view $=$ article\&id $=42 \&$ Itemid $=75$

Tolson, B. A., \& Shoemaker, C. A. (2007). Dynamically dimensioned search algorithm for computationally efficient watershed model calibration. Water Resources Research, 43. 